\title{
Alianças entre o Terceiro Setor, a Universidade e os Sistemas Públicos: pela melhoria dos Processos Educacionais em Arte
}

\section{Alliances among the Third Sector, the University and the Public Systems towards a better educational process in art}

\author{
Evelyn loschpe*
}

\begin{abstract}
RESUMO
O artigo relata a interação entre uma entidade do Terceiro Setor - a Fundação Iochpe e seu Instituto Arte na Escola - com uma rede de 53 universidades brasileiras por meio de suas pró-reitorias de extensão. A Rede Arte na Escola se dedica a capacitar professores de Arte do ensino público. O artigo discute a interface entre entidade do Terceiro Setor e a Universidade, problematizando o relacionamento que esta última mantém com a comunidade maior, ainda excessivamente distante.
\end{abstract}

Palavras-chave: Projetos extensionistas; interfaces; terceiro setor.

\section{ABSTRACT}

This article refers to the interaction between a philanthropic entity - The lochpe Foundation and its Arts in School Institute- with a network of 53 Brazilian universities, through their extension course deanships. The network Arts in School focuses on the training of art teachers for the public school system. The article discusses the interface between a philantropic entity and the University, and the problematic relationship that the latter maintains with the community at large, which is still excessivel.

Keywords: Extension projects; interfaces; third sector.

\section{RESUMEN}

\begin{abstract}
El artículo relata la interacción entre una entidad del Tercer Sector- la Fundación Iochpe y su Instituto Arte en la Escuela- con la red de 53 universidades brasileñas por medio de sus pro-rectorías de extensión. La Red Arte en la Escuela se dedica a la capacitación de profesores de Arte de la enseñanza pública. El artículo discute el interfaz entre una entidad del Tercer Sector y la Universidad, problematizando la relación que mantiene la última con la comunidad más amplia que es aún excesivamente lejana.
\end{abstract}

Palabras-clave: projectos de extensión; interfaz; tercer sector.

A Fundação Iochpe, entidade do Terceiro Setor voltada para Educação, desenvolveu tecnologias sociais em rede para seus programas Formare e Arte na Escola. No primeiro, voltado para educação técnica profissional, a parceria é realizada com empresas privadas. No Arte na Escola foi desenvolvida uma rede relacional com universidades, majoritariamente públicas, através de suas Pró-Reitorias de Extensão. O presente artigo pretende analisar esta última tecnologia social, buscando entende-la e discutir suas premissas.

Socióloga e jornalista pela UFRGS e especialista em Educação em Museus pela Universidade de York, Inglaterra, atualmente Diretora Presidente do Instituto Arte na Escola. 


\section{Um pouco de história}

A Fundação Iochpe foi criada em 1989 no Rio Grande do Sul pelas empresas lochpeMaxion buscando dar maior foco e estratégia às múltiplas ações voltadas para a comunidade que a empresa habitualmente patrocinava. Partindo da tradição do Mecenato Cultural no qual a empresa se destacara na década de 80, a deliberação foi de investir de maneira mais duradoura buscando resultados de longo prazo, focando agora em Educação - vista como questão estratégica para o desenvolvimento.

Uma oportunidade acabou gerando a linha de trabalho a qual nos dedicaríamos: o governo do Estado do Rio Grande do Sul estava criando um novo equipamento cultural - a Casa de Cultura Mário Quintana - em que desejava instalar uma videoteca. A idéia parecia interessante, mas teria relevância social? Seria útil para o ensino de Arte, como se propunha? Por meio de consultoria com a Dra. Ana Mae Barbosa da USP, decidimos conduzir uma pesquisa-ação para entender a utilidade do uso dos vídeos na sala de aula de Artes, considerando a nova Metodologia Triangular que vinha sendo proposta.

Os resultados da pesquisa conduzida pelas Professoras Analice Dutra Pillar e Denyse Vieira, publicados em $O$ vídeo e a metodologia triangular no ensino da Arte apontam para a ocorrência de alterações significativas. Isso se reflete, não só nos processos dos alunos (se desenvolveram no fazer artístico, em duas e três dimensões, na leitura e na contextualização histórica das imagens) como também no trabalho dos professores (os planos de ensino para o ano seguinte tinham unidade, seqüência, estrutura, flexibilidade, integração entre os conteúdos, e os professores mostravam-se mais estimulados, mais bem informados e preparados). ${ }^{1}$

No capítulo inicial do livro as pesquisadoras historiam os pressupostos do ensino da Arte, evidenciando a transição de uma abordagem modernista (a livre- expressão) para outra contemporânea (a triangular), pois "era necessário adotar uma abordagem mais substancial e abrangente para elevar a qualidade do ensino da Arte nas escolas". ${ }^{2}$ Elas relatam como uma metodologia concebida na Inglaterra e nos Estados Unidos nos anos 1960 foi adaptada para o contexto brasileiro envolvendo três vertentes: o fazer artístico, a leitura da imagem e a história da Arte. E concluem afirmando que a função primordial da Arte-educação na escola é a formação estética dos indivíduos, que os levem a um entendimento da gramática visual e a uma reflexão acerca das imagens. O objetivo, portanto, não é criar artistas, mas ajudar a desenvolver leitores de Arte.

Com os resultados, tínhamos não apenas a convicção de que o uso de vídeos e da metodologia agregava valor à aula de Artes, mas também que o direcionamento que havíamos tomado de realizar o trabalho em parceria com a Universidade (Pró-Reitoria de Extensão) e o Poder Público (Secretaria de Educação do Município) era além de promissor, o único que poderia garantir a perenidade e o enraizamento da ação e, conseqüentemente, de seus benefícios.

Abandonamos, portanto, a idéia inicial de alocar vídeos em instituição cultural pública para constituir uma Videoteca multiplicável que pudesse subsidiar os esforços das universidades na formação dos professores - especialmente em Educação Continuada. Por que op-

\footnotetext{
$1 \quad$ PILLAR, Analice Dutra; VIEIRA, Denyse. O vídeo e a metodologia triangular no ensino da Arte. Porto Alegre: Universidade Federal do Rio Grande do Sul: Fundação Iochpe, 1992.

2 ibidem.
} 
tar pela parceria com a universidade, ao invés da instituição pública? Enquanto o poder público no Brasil se caracteriza por mudanças radicais a cada quatro anos, a Universidade tem tido estabilidade em seus programas independentemente de gestões específicas. A esta (relativa) estabilidade se somava outro fator determinante de nossa escolha: ao longo da pesquisa-ação desenvolvida entre 1990 e 1991, em que vários processos de capacitação de professores foram realizados, ficou claro que a Universidade seria o ambiente natural e propício para o desenvolvimento do trabalho. Não só sua estrutura física está desenhada para a finalidade didática que realiza, como esta é a sua própria e primordial razão de existir.

A Fundação Iochpe entendeu que este modelo geraria a sustentabilidade da iniciativa, na medida em que cada parceiro poderia realizar sem maior esforço aquilo que é sua função inerente. A universidade enquanto depositária e transmissora do conhecimento - no caso, nas áreas de Arte e educação - tem como responsabilidade devolver este saber à sociedade. Foi nosso entendimento que ao produzirmos e encaminharmos materiais de apoio ao ensino às Universidades, para que estas os disponibilizem aos seus públicos, estávamos enriquecendo os acervos capazes de gerar a multiplicação do conhecimento e ainda favorecendo a pesquisa. Não é necessário acrescentar que a Universidade dispõe das condições de realizar as funções detalhadas no convênio: guarda e empréstimo da Midiateca e Educação Continuada dos professores da rede pública. Caberia, portanto a uma fundação de natureza privada buscar tão somente complementá-la, adicionando a agilidade, os recursos e a gestão que uma entidade do Terceiro é capaz de ter por sua própria natureza.

Esta lógica, aparentemente óbvia, não apareceu desde o seu nascedouro. $\mathrm{O}$ primeiro convênio da Fundação Iochpe foi firmado pela Pró-Reitoria de Extensão da Universidade Fe- deral do Rio Grande do Sul, na figura do Dr. Waldomiro Manfrói em 1991. Sua ratificação pelo Conselho Universitário consumiu tempo e argumentação difíceis de prever para quem estava realizando uma doação: questionava-se quais seriam as "reais intenções" de uma empresa privada da área metal-mecânica ao investir em processos educacionais em Arte. Naquele momento em que o Terceiro Setor recém se estruturava e que eram raras as iniciativas com este perfil, estas dúvidas (embora surpreendentes) foram absorvidas considerando o marco ideológico que pautava o corpo docente universitário: um "neo-marxismo" genericamente avesso ao capital privado. Basta lembrar a emblemática figura de Betinho que nesta época dizia

\begin{abstract}
Pertenci a uma geração em que empresário era o diabo da sociedade. E se era grande empresário, diabo grande - se era pequeno empresário, diabo pequeno. Hoje estamos noutro mundo, em outra sociedade e pensamos que o grande empresário tem imensa responsabilidade, $\mathrm{o}$ médio responsabilidade média e o micro responsabilidade menorzinha de mudar o Brasil.
\end{abstract}

Entender a postura acadêmica vigente na época nos fez repensar a identidade do projeto. Decidimos utilizar apenas a marca do Arte na Escola para identificá-lo na universidade, sem menção à Fundação ou a empresa patrocinadora. Profissionais de marketing poderão analisar o acerto ou não desta estratégia. Como consumidora devo dizer que até hoje, em plena febre do "marketing relacionado a causas" tenho grandes dúvidas sobre sua utilidade e eficácia. De qualquer forma, de parte da Companhia lochpe-Maxion, não se tratava de ação de marketing e sim deliberação do Conselho de efetivamente devolver à sociedade recursos que haviam sido propiciados pela mesma. Iniciamos, 
pois, o então chamado "Projeto Arte na Escola" por meio da assinatura de convênio com a Universidade Federal do Rio Grande do Sul e a Secretaria de Educação Municipal de Porto Alegre. Para a ocasião auspiciosa levamos a Porto Alegre um dos maiores "scholars" mundiais da Arte-Educação: o Prof. Dr. Elliot Eisner da Universidade de Stanford, autor de quinze livros de referência na área, que além de ter recebido prêmios importantes como Fullbrigth $e$ Guggenheim, presidiu a International Society for Education Throught Art (INSEA).

A modelagem inicial do Projeto Arte na Escola foi influenciada também pelo aprendizado que a agência americana USIS nos proporcionou ao montar um périplo pelos Estados Unidos para conhecer experiências destacadas de Arte-educação. Tomar contato com o gigantesco trabalho do Getty Institute e sua ligação com algumas universidades americanas reforçou nosso desenho estratégico e abriu oportunidade para que vários Arte-educadores brasileiros $^{3}$, desde 1991, freqüentassem os Summer Institutes de capacitação para professores operados por universidades americanas. Esta experiência de aprendizado logo encontrou seu vetor de retorno e fez com que produzíssemos um pôster de Arte brasileira com seu respectivo material educacional em parceria com The Getty Center for Education in the Arts, a University of Tennessee at Chattanooga, o Museu Lasar Segall e a Pinacoteca do Estado de São Paulo. Vários de nossos Arte-educadores convidados não só receberam aulas, mas também repartiram sua experiência com os colegas americanos.

Com o trabalho iniciado, constituímos a Videoteca Arte na Escola, cujos 248 títulos foram selecionados pelo cineasta Henrique Freitas Valle levando em consideração questões de conteúdo e forma. Foi igualmente realizado o esforço de criação de um Material Educacional para cada vídeo, patrocinados pela Fundação Vitae. Obtivemos recursos do Ministério da Educação para a compra de um aparelho Record Play Laser, que ficou lotado na UFRGS, e que nos possibilitava prensar uma matriz de cada vídeo para o qual havíamos adquirido os direitos de reprodução e, portanto fazer cópias para distribuir. A partir de demanda do próprio MEC oferecemos às demais universidades federais gaúchas a possibilidade de participarem do Arte na Escola. A Universidade Federal de Pelotas aderiu e, posteriormente, uma universidade de natureza comunitária - a Universidade de Caxias do Sul - veio se juntar ao que começava a se transformar numa Rede. Uma universidade federal se manifestou contrariamente a adesão: a de Santa Maria. Entender a lógica desta universidade fez com que deliberássemos, então, pautar nossa expansão unicamente na demanda das universidades, e não numa oferta pró-ativa. Em 1994 a Rede Arte na Escola assinou nova etapa de expansão, consolidando seu trabalho em 08 Pólos Universitários ${ }^{4}$ e um Museu. Prosseguíamos com nossa proposta inicial de reforçar a linha de trabalho de Formação Continuada para os docentes de Arte das redes públicas, instrumentalizá-los com material educacional de qualidade e incentivar as iniciativas universitárias por "grants" específicos para este fim.

O Programa Arte na Escola tem por missão qualificar processos educacionais em Arte e abrange programas na área de Arte-educação consistentes em:

Amanda Tojal, Rosa lavelberg, Iveta Maria Fernandes, Dora Maria Dutra Bay, Denise Grinspum, Elizabeth Militisky Aguiar, Mari Lucie da Silva Loretto, Tarsisio Sapienza, Heloisa Margarido Salles, Maria Cristina Biazus, Maria Helena Wagner Rossi, Sebastião Pedrosa, Marlene Ramires Françoise, Milene Chiovatto.

4 Universidade Federal do Rio Grande do Sul - UFRGS, Universidade de Caxias do Sul - UCS, Universidade Federal de Pelotas UFPEL, Universidade do Estado de Santa Catarina - UDESC, Universidade Federal do Paraná - UFPR, Universidade Federal da Paraíba - UFPB, Universidade Federal do Pará - UFPA e Museu Lasar Segall. 
a) Educação Continuada, que visa, por meio da manutenção de grupos de estudos e a realização de seminários, palestras e outras atividades presenciais e/ou à distância, a qualificação do professor das redes públicas de ensino;

b) Midiateca, que proporciona o empréstimo de acervo de DVDs especializados em Artes visuais com seus respectivos materiais de apoio ao ensino.

Para entender como funciona o Arte na Escola na prática as universidades-pólo destinam um espaço físico à Midiateca e realizam o empréstimo dos títulos aos professores das redes públicas de ensino sem ônus para os mesmos. Estas universidades, ao operar os programas de Educação Continuada, praticam ação extensionista, entendida aqui conforme definição do Plano Nacional de Extensão Universitária de 1999:

\begin{abstract}
A ação cidadã das universidades não pode prescindir da efetiva difusão dos saberes nelas produzidos, de tal forma que as populações cujos problemas tornamse objeto da pesquisa acadêmica sejam também consideradas sujeito desse conhecimento, tendo, portanto, pleno direito de acesso às informações resultantes dessas pesquisas.
\end{abstract}

Novo salto de crescimento ocorreu em 2003, quando abrimos edital para que as universidades públicas de todo o Brasil viessem a integrar a Rede Arte na Escola. O respaldo técnico veio do Fórum Nacional de Pró-Reitores de Extensão das Universidades Públicas, com o qual assinamos Acordo Operacional num momento em que este lograra produzir instrumento de Avaliação para a Extensão Universitária pela publicação do volume "Avaliação Nacional de Extensão Universitária" (2001).
Acreditamos que fomos o primeiro projeto a utilizar esta ferramenta de avaliação gestada ao longo de muitos anos de trabalho do Fórum de Pró-Reitores de Extensão, o que nos permitiu desenvolver parâmetros muito objetivos para a admissão de novas universidades na Rede que havíamos iniciado no Sul no inicio dos anos 90. O Fórum participou conosco do Comitê de Seleção e assim logramos chegar ao novo milênio com mais de 50 pólos selecionados e implantados, num processo de avaliação entre pares que visava garantir condições adequadas de funcionamento do programa. As pré-condições para candidatura a este edital foram:

- Ser Instituição do Ensino Superior Pública (Municipal, Estadual e Federal);

- Estar nas cidades de maior população escolar de $5^{\mathrm{a}}$ a $8^{\mathrm{a}}$ séries;

- Ter a Extensão Universitária institucionalizada;

- Desenvolver atividades em Arte-educação;

- Trabalhar em parceria com as Redes Públicas.

$\mathrm{O}$ acelerado crescimento do Arte na Escola neste período gerou a necessidade de uma nova institucionalidade: formalizamos a criação do Instituto Arte na Escola, que assim se desmembrou da Fundação Iochpe. Os Arteeducadores presentes no Encontro Anual da Rede de 1999 reunidos em Assembléia Geral tornaram-se os sócios-fundadores desta instituição privada sem fins lucrativos. Posteriormente outros nomes exponenciais na Arte-educação foram convidados e subscreveram a fundação da entidade. Desde então o Instituto Arte na Escola é uma organização não-governamental mantida pela Fundação Iochpe, patrocinadores e por receitas próprias. É dotada de Conselho Deliberativo composto por 09 membros e Conselho Fiscal composto de 03 membros, tendo seus números auditados anualmente, e publicados com transparência no site www.Artenaescola.org.br. As questões de 
governança também impactaram esta organização e a levaram a se constituir, em 2007 numa OSCIP - Organização da Sociedade Civil de Interesse Público, que é a nova geração das Organizações Sociais preocupadas com transparência na gestão.

Uma crença básica sustenta este trabalho: a de que o Brasil só vai ser competitivo globalmente quando alcançarmos patamares sólidos e maduros de educação e de que isto se logra capacitando o professor de forma continuada e sustentada. Estamos nos referindo, no caso do Arte na Escola, ao professor de Artes, sempre que ele está presente na escola. Autoridades do MEC falam em $75 \%$ como o índice de professores nas aulas de Arte não formados em Arte.

Desde o início dos anos 1990 nossa aposta é na potencialidade da Extensão Universitária e na sua vontade política de agir estendendo os benefícios do saber acadêmico à comunidade maior.

Ao se afirmar que a extensão é pArte indispensável do pensar e fazer universitários assume-se uma luta pela institucionalização dessas atividades, tanto do ponto de vista administrativo como acadêmico, o que implica a adoção de medidas e procedimentos que redirecionam a própria política das universidades. $^{5}$

E aí chegamos ao nó da questão: embora formalmente este reconhecimento exista e estejamos vendo uma grande expansão de pro- jetos lotados na Extensão, o fato é que esta ainda detém pouco prestígio quando comparada ao Ensino e Pesquisa. O tripé em que a vida universitária se assenta não tem equivalência $e$, portanto equilíbrio. O ensino - aprendizagem se constitui no eixo primordial da vivência universitária e se confunde com a sua própria razão de ser. As exigências que são feitas sobre o professor para a publicação faz com que a pesquisa se fortaleça como um segundo vetor que justifica alocação importante de verbas. Poderia se questionar a relevância do que se pesquisa ou a finalidade para qual se pesquisa, já que pArte significativa deste esforço acaba circunscrita à própria Academia. Em contraste com esta postura a idéia de Extensão, segundo a Wikipedia está associada à crença de que o conhecimento "gerado pelas instituições de pesquisa deve necessariamente possuir intenções de transformar a realidade social, intervindo em suas deficiências e não se limitando apenas à formação dos alunos regulares daquela instituição". ${ }^{6}$

A realidade social brasileira indica que sua Educação Básica, avaliada pelo PISA em 2006, nos deixa num embaraçoso $53^{\circ}$ lugar em Matemática e no $48^{\circ}$ em Leitura entre os 57 países analisados. Qual o papel da Universidade, por meio do ensino, pesquisa e extensão para equacionar este monumental déficit? Se temos uma universidade que em muitas áreas do conhecimento se ombreia com as melhores no mundo, como entender que a pesquisa educacional nela gerada não consiga melhorar o desempenho da Educação como um todo? Como construir conhecimento se não se volta ao próprio processo desta construção?

\footnotetext{
PLANO NACIONAL DE EXTENSÃO UNIVERSITÁRIA. Edição atualizada. Brasil, 2000- 2001. Fórum de Pró-Reitores de Extensão das Universidades Públicas Brasileiras e SESu / MEC. Disponível em:

<http://209.85.215.104/search?q=cache:0SxWeAg0cm0J:www.ufac.br/pro_reitorias/pr_assunt_comunitarios/doc_ass_comunitarios/ doc_prac_plano_extensao_universitaria.doc+ao+se+afirmar+que+a +extens\%C3\%A3o+\%C3\%A9+Arte +indispens\%C3\%A1vel+ $\mathrm{do}+$ pensar $+e+$ fazer + universit\%C3\%A1rios\&hl=pt-BR\&ct=clnk\&cd=1\&gl=br $>$. Acesso em: jun. 2008.

6 EXTENSÃO UNIVERSITÁRIA. Disponível em: < http://pt.wikipedia.org/wiki/Extens\%C3\%A3o_universit\%C3\%A1ria >. Acesso em: jun. 2008
} 
Utilizar a Extensão Universitária que se conecta com uma sociedade pulsante e suas necessidades reais para alimentar a pesquisa ainda não é uma prática corrente. O Arte na Escola estimula esta atitude que faz gerar um professor - pesquisador atento à sua realidade, que aprofunda seus processos e sistematiza o aprendizado que esta lhe traz. A REDE ARTE NA ESCOLA contabilizou várias pesquisas voltadas à concretude do ensino de Arte nas redes públicas e que investigam o próprio trabalho extensionista realizado pelo Pólo:

FRANCISCO, Sandra Suely dos Santos. A formação continuada de professores de Arte da região metropolitana de Belém na perspectiva da parceira. 2007. 94 f. Dissertação (Mestrado em Educação) - Universidade de Uberaba - Uniube, 2007.

NASCIMENTO, Erinaldo Alves do. Mudanças nos nomes da Arte na educação: qual infância? que ensino? 2005. 254 p. Tese (Doutorado em Artes) - Escola de Comunicações e Artes da Universidade de São Paulo - ECA/USP, São Paulo, 2005.

PILLOTTO, Silvia Sell Duarte. O ensino da Arte na educação infantil. 1997. Dissertação (Mestrado em Educação) - Universidade Federal do Paraná - UFPR, Curitiba, 1997.

Os Coordenadores de Pólos Arte na Escola, igualmente, vem se envolvendo na elaboração dos Referenciais Curriculares de Arte nos sistemas municipais e estaduais de ensino. Neste momento temos ciência de trabalho nesta direção de Arte de: Vera Lúcia Penzo Fernandes e Ana Lúcia Serrou Castilho, do Pólo Arte na Escola na Universidade Federal do Mato Grosso do Sul (UFMS), que participaram da elaboração do referencial curricular da Rede Municipal de Campo Grande (MS); Silvia Sell Duarte Pillotto, do Pólo Arte na Escola da Uni- versidade da Região de Joinville (UNIVILLE), que contribuiu com a proposta curricular de Santa Catarina, escrevendo um volume sobre a formação docente e Erinaldo Alves do Nascimento, que foi coordenador do Pólo Arte na Escola da Universidade Federal da Paraíba (UFPB) e prestou consultoria na construção da proposta curricular do Estado de Sergipe. Iniciam a redação, igualmente, Ana Mariza Filipouski, (UFRGS) e Isabel Petry da FUNDARTE, ambas no Rio Grande do Sul.

$\mathrm{O}$ envolvimento destes professores na reflexão sobre o que e como se ensina nas redes de ensino de nível fundamental e médio é, do nosso ponto de vista, a verdadeira expressão da influência que a (boa) academia pode ter sobre a Educação de um país entendida como um processo de inclusão social. Só professores universitários que não perderam a sensibilidade (e o conhecimento) do que efetivamente se passa na sala de aula podem ser propositores da arquitetura do ensino em suas regiões.

No que diz respeito à pesquisa, são autores norte-americanos que lograram estabelecer o impacto do ensino de Arte na educação como um todo. São estas pesquisas ${ }^{7}$ que nos informam da correlação negativa existente, por exemplo, entre um bom programa de Arte e os índices de evasão escolar. Hoje sabemos que apenas $37 \%$ do contingente que ingressa nas primeiras séries, no Brasil, cumpre os 12 primeiros anos de escolaridade. Portanto, além das considerações quanto à importância do ensino da Arte per se, e como se não bastassem, temos hoje a clara percepção da importância de bons programas de Arte para reter esta população de $63 \%$ de crianças e jovens na escola.

O Arte na Escola aposta no tripé ENSINO-PESQUISA-EXTENSÃO universitárias para encontrar soluções efetivamente calcadas

ARTS Education Partnership. Research. Disponível em: 
em nossa realidade, que sejam eficazes e efetivas para a sociedade como um todo.

Pela sua prática, que presentemente soma 19 anos, vem comprovando a possibilidade de um processo de mútua influência entre Terceiro Setor e Universidade visando causar impacto sobre os indicadores educacionais bra-

\section{REFERÊNCIAS}

ALEXANDER, Kay; DAY, Michael (Ed.). Discipline-based art education: a curriculum sampler. Los Angeles: Getty Center for Education in the Arts, 1991.

ARNHEIM, Rudolf. Thoughts on art education. Los Angeles: Getty Center for Education in the Arts, 1989. (Occasional papers, 2).

BARBOSA, Ana Mae. A imagem no ensino da Arte: anos oitenta e novos tempos. São Paulo: Perspectiva; Porto Alegre: Fundação Iochpe, 1991. (Estudos, 126).

EISNER, Elliot W. Reimagining schools: the selected works of Elliot W. Eisner. London: Routledge, 2005. (World library of educationalists).

The enlightened eye: qualitative inquiry and the enhancement of educational practice. Upper Saddle River: Prentice-Hall, 1998.

GARDNER, Howard. Art education and human development. Los Angeles: Getty Center for Education in the Arts, 1990. (Occasional papers, 3).

HERNÁNDEZ, Fernando. Cultura visual, mudança educativa e projeto de trabalho. Trad. Jussara Haubert Rodrigues. Consultoria, supervisão e revisão técnica Mirian Celeste Martins. Porto Alegre: Artmed, 2000. sileiros e, conseqüentemente, sobre o modelo de desenvolvimento da Educação brasileira. A maneira como a maioria dos 53 pólos universitários assumiu como seu o trabalho, nos dá esperanças de uma nova postura acadêmica efetivamente comprometida com os destinos da nação.

IOSCHPE, Evelyn Berg (Org.). $3^{\circ}$ Setor: desenvolvimento social sustentado. Textos Ruth Cardoso et al. 3.ed. São Paulo: Gife: Paz e Terra, 2005. Trabalhos apresentados no III Encontro Ibero-Americano do Terceiro Setor em setembro de 1996.

IOSCHPE, Gustavo. A ignorância custa um mundo: o valor da educação no desenvolvimento do Brasil. São Paulo: Francis, 2004.

PARSONS, Michael J. Cómo entendemos el Arte: una perspectiva cognitivo-evolutiva de la experiencia estética. Barcelona: Paidós, 2002. (Arte y educación, 3).

PERKINS, David N. The intelligent eye: learning to think by looking at art. Santa Monica: Getty Center for Education in the Arts, 1994. (Occasional papers, 4).

PILLAR, Analice Dutra; VIEIRA, Denyse. O vídeo e a metodologia triangular no ensino da Arte. Porto Alegre: Universidade Federal do Rio Grande do Sul: Fundação Iochpe, 1992.
Texto recebido em 30 jun. 2008

Texto aprovado em 10 set. 2008. 